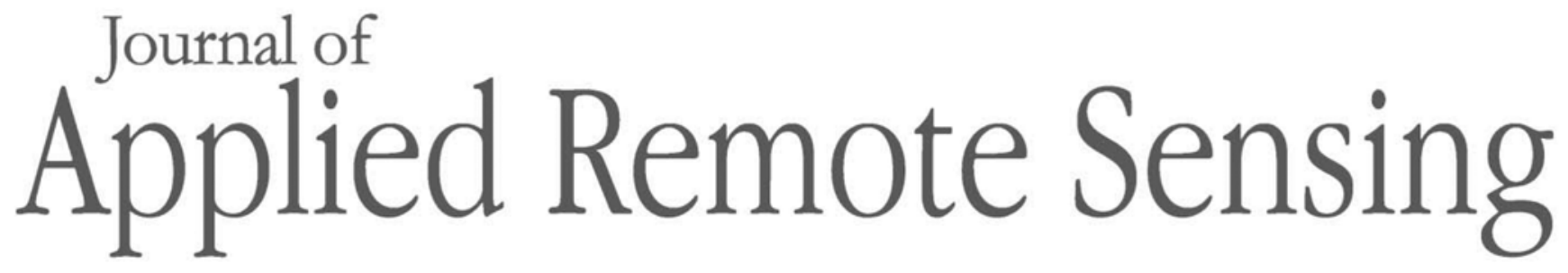

RemoteSensing.SPIEDigitalLibrary.org

\title{
Special Section Guest Editorial: \\ Recent Advances in Earth \\ Observation Technologies for \\ Agrometeorology and Agroclimatology
}

Shibo Fang
Davide Cammarano
George Petropoulos 


\title{
Special Section Guest Editorial: Recent Advances in Earth Observation Technologies for Agrometeorology and Agroclimatology
}

\author{
Shibo Fang, ${ }^{\text {a,b }}$ Davide Cammarano, ${ }^{\mathrm{c}}$ and George Petropoulos ${ }^{\mathrm{d}}$ \\ ${ }^{a}$ State Key Laboratory of Severe Weather, Chinese Academy of Meteorological Sciences, \\ Beijing, China \\ ${ }^{\mathrm{b}}$ Collaborate Innovation Center on Forecast and Evaluation of Meteorological Sciences, \\ Nanjing University of Information Science and Technology, Nanjing, China \\ ${ }^{c}$ The James Hutton Institute, Invergowrie, Scotland, United Kingdom \\ dinstitute of Forage \& Industrial Crops, Department of Soil \& Water Resources, \\ Agricultural Organisation "DEMETER" (formerly NAGREF), \\ Directorate for Agricultural Research, Ministry of Agriculture, Larisa, Greece
}

Crops are sensitive to changes in temperature and $\mathrm{CO}_{2}$ and extreme weather patterns, and are more vulnerable to extreme climate events and extreme weather (serious drought, flood, severe hot or cold), which will occur more frequently in the future as the Intergovernmental Panel on Climate Change predicts. The regular and timely monitoring of crop health condition, crop growth and development, and the effects of climate variability and change on crops' growth and development at regional and local scale are vital for economic and environmental purposes. Remote sensing has shown a high potential to provide valuable information regarding the extent, status, and management of agricultural land at various spatial and temporal scales.

In the past 20 years, a large number of space-borne sensors have developed. In particular, new sensors, such as synthetic aperture radar (SAR) and passive microwave, have extended Earth observation capacity.

Many indexes and methods of soil moisture (related to drought and waterlogging, etc.), crop stresses (drought, waterlogging, extreme hot or cold leading to stressed crop conditions or crop damage), and plant/vegetation phenology response to climate change, have been developed and practiced.

However, most methods have their own application conditions and boundaries, such as soil thermal inertia method used to retrieve soil moisture in less vegetation cover durations, but most vegetation health indices were employed when the canopy covered the surface. Until now, many methods had been practiced without any onboard calibration or without precision evaluation and accuracy assessment but rely on other processing (modeling or ground truth parameters). The practical ability of different remote sensing methods is essential to ensuring that all of the retrieved data have a reliable and stable accuracy in spatial and temporal variations.

This special section focuses on the use of remote sensing tools for agrometeorological/ agroclimatological applications in the areas of agrometeorological disaster (drought, flood, hot or cold weather) and climate change impacts on crops and grass land. Half of the papers in this special section focus on soil moisture retrieving methods or address crop response to drought stress. New water supplying capacity indices of soil were created and evaluated in southwest China. A new soil moisture index of active microwave remote sensing (SAR) was developed and calibrated in Germany. Leaf water content was estimated by mid- and thermal-infrared spectra of optical remote sensing, which has potential capacity to quantify water stresses in vegetation. The reliabilities of several widely used drought indices were compared over a whole maize growth period in China. A soil moisture retrieval method of unmanned aerial also was included in this special section. In addition, several papers were included to address the crops' growth condition, phenology dynamics driven by meteorological factors, and climate changes.

We would like to extend our appreciation to the authors who submitted their research for inclusion in this section. Our thanks also go to the efforts of the many reviewers for their critical comments in ensuring the highest quality in the research presented in this special section. 